\title{
Impact of erenumab on acute medication usage and health care resource utilization among migraine patients: a US claims database study
}

\author{
Stewart J. Tepper ${ }^{1}$, Juanzhi Fang ${ }^{2 *}$, Pamela Vo ${ }^{3}$, Ying Shen ${ }^{4}$, Lujia Zhou ${ }^{4}$, Ahmad Abdrabboh²,
} Mrudula Glassberg ${ }^{2}$ and Matias Ferraris ${ }^{3}$

\begin{abstract}
Background: Migraine is one of the leading causes of disability worldwide. Erenumab is a fully human monoclonal antibody that targets the calcitonin gene-related peptide (CGRP) receptor. This study aimed to evaluate real-world evidence on the impact of erenumab on acute medication usage and health care resource utilization (HCRU) among migraine patients.

Methods: This retrospective effectiveness study utilized the US Optum's de-identified Clinformatics ${ }^{\circledast}$ Data Mart database to identify migraine patients initiating erenumab between May 1, 2018 and September 30, 2019. Patients had to be at least 18 years old, with a minimum of three doses for erenumab in the 6-month post-index period and continuous medical/pharmacy coverage in the 12-month pre- and 6-month post-index period. The date of the first claim for erenumab served as the index date. Use of acute medications overall and at different drug class level, and HCRU were compared during the 6-month pre- vs. post-index period. Impact of erenumab on a composite endpoint of three possible events: 1) outpatient visit with a diagnosis of migraine and an associated acute medication claim within 7 days of the visit, 2) hospital admission with a primary diagnosis for migraine, or 3) emergency room visit with a primary diagnosis for migraine (any events that occurred $\leq 3$ days apart were counted only once) was also evaluated.
\end{abstract}

Results: The analysis included 3171 identified patients. At 6 months, following initiation of erenumab, acute medication use including the number of types of acute medication, number of claims of each medication and $\%$ of patients who received acute medication, and HCRU were significantly decreased. For the composite outcome, the mean number of events decreased from 1.03 to 0.77 (rate ratio: $0.75 ; 95 \% \mathrm{Cl}: 0.71$ to $0.79 ; P<0.0001$ ). A decrease in the proportion of patients with any of the three events was also observed $(52.7 \%$ vs. $39.5 \%, P<0.0001)$.

Conclusion: In this retrospective analysis, erenumab was associated with significantly reduced acute medication use and $\mathrm{HCRU}$ in a real-world setting, hence significantly reducing the burden of the disease. A composite endpoint could be used as a proxy to evaluate the burden of migraine attacks; however, further research is needed.

Keywords: Burden, Efficacy, Erenumab, Health care resource utilization, Migraine, Preventive therapies, Real-world evidence

\footnotetext{
* Correspondence: jenny.fang@novartis.com

${ }^{2}$ Novartis Pharmaceuticals Corporation, East Hanover, NJ, USA

Full list of author information is available at the end of the article
}

C C The Author(s). 2021 Open Access This article is licensed under a Creative Commons Attribution 4.0 International License, which permits use, sharing, adaptation, distribution and reproduction in any medium or format, as long as you give appropriate credit to the original author(s) and the source, provide a link to the Creative Commons licence, and indicate if changes were made. The images or other third party material in this article are included in the article's Creative Commons licence, unless indicated otherwise in a credit line to the material. If material is not included in the article's Creative Commons licence and your intended use is not permitted by statutory regulation or exceeds the permitted use, you will need to obtain permission directly from the copyright holder. To view a copy of this licence, visit http://creativecommons.org/licenses/by/4.0/ The Creative Commons Public Domain Dedication waiver (http://creativecommons.org/publicdomain/zero/1.0/) applies to the data made available in this article, unless otherwise stated in a credit line to the data. 


\section{Background}

Migraine is a common neurological disorder characterized by recurrent attacks of moderate-to-severe headaches and accompanying symptoms (nausea, vomiting, and sensitivity to light, sound, or smell), and is one of the leading causes of disability worldwide [1, 2]. Depending on the frequency and regularity of symptoms, migraine can either be categorized as episodic migraine (EM), defined as < 15 headache days per month, or chronic migraine (CM), defined as $\geq 15$ headache days per month for more than 3 months, of which $\geq 8$ days have features of migraine [2]. In the United States (US), an estimated $19 \%$ of individuals in their peak employment years, aged 18-54 years, experience debilitating migraines, such that the condition presents an enormous economic burden for patients, health systems, employers, and society [3]. Pharmacologic treatment of migraine involves both acute and preventive therapy [4-6]. Acute medications aim to provide a sustained pain-free response for a given attack and include migraine-specific medications (triptans and ergots, and more recently lasmiditan and gepants) and nonspecific medications (e.g. nonsteroidal anti-inflammatory drugs [NSAIDs], opioids, and barbiturates) [7]. Although opioids and barbiturates are used clinically, these are not recommended for acute management. Preventive therapies aim to reduce the frequency, severity, duration of attacks, and the impact on quality of life of future migraine headaches. Preventive medications include beta blockers, anticonvulsants, antidepressants, onabotulinumtoxinA (onabotA) injection therapy, and anti-calcitonin gene-related peptide (CGRP) monoclonal antibody (mAb) drugs [8]. Historically, preventive treatment has involved the use of medications, originally developed for other conditions [9], and oral versions have been subject to poor adherence, mainly due to suboptimal efficacy and tolerability [10-12].

Erenumab (in the US, erenumab-aooe) was developed to specifically target the CGRP pathway, which plays a key role in the pathophysiology of migraine [13]. Erenumab, approved in the US for the preventive treatment of migraine in adults in May 2018, is a fully human mAb that selectively binds to and inhibits the CGRP receptor $[14,15]$. The efficacy and safety of erenumab in migraine patients have been evaluated in multiple clinical trials [5, $9,10,16-20]$, showing a significant reduction in the mean change from baseline in monthly migraine days $[16,21]$. In addition, post-hoc analyses have shown significant improvements in quality of life and disability scales [22]. A recently published real-world audit in 'hard to treat' chronic migraine sufferers (all of whom had tried and discontinued multiple migraine preventatives including onabotA), found that erenumab showed significant improvements in the number of headache days, medication use and measures of functional performance [16, 23]. Further real-world evidence on the impact of erenumab on patients with migraine is growing $[24,25]$. This study evaluated the real-world impact of erenumab on acute medication usage and health care resource utilization (HCRU) among adult migraine patients in the US. A subgroup analysis reviewed whether erenumab can be effective in patients with more severe migraine phenotypes, including those with a prior unsatisfactory response to onabotA. OnabotA has a relatively higher cost compared to oral migraine preventative medications and has a requirement to be administered in a clinic by trained health care providers (HCPs), making it generally reserved for patients with CM [23].

\section{Methods}

Study design and data sources

This study was a retrospective, exploratory treatment effectiveness, non-interventional, observation analysis using Optum's de-identified Clinformatics ${ }^{\oplus}$ Data Mart (CDM) database, 1st version, 2019 (Fig. 1 and Supp Table 1).

Optum's CDM is a database of administrative health claims for members of large commercial and Medicare Advantage health plans. The database includes approximately 17-19 million annual covered lives, for a total of over 68 million unique lives over an 11-year period (1/2007 through 9/2019). It is statistically de-identified under the Expert Determination method consistent with the Health Insurance Portability and Accountability Act (HIPAA) and managed according to Optum customer data use agreements. CDM administrative claims submitted for payment by providers and pharmacies are verified, adjudicated, and de-identified prior to inclusion. These data, including patient-level enrollment information, are derived from claims submitted for all medical and pharmacy health care services. The population is geographically diverse, spanning all 50 US states. As the study used only existing de-identified patient records and analyses of health care claims, data do not meet the definition of human subject research, so Institutional Review Board approval and patient informed consent were not required. No identifiable private information or protected health information was provided. This study was conducted in accordance with the Guidelines for Good Pharmacoepidemiology Practices (GPP) of the International Society for Pharmacoepidemiology (ISPE) 2016, the Strengthening the Reporting of Observational Studies in Epidemiology (STROBE) guidelines, and with the ethical principles laid down in the Declaration of Helsinki.

\section{Patient selection}

Adults ( $\geq 18$ years of age) with $\geq 1$ prescription fill for erenumab between May 1, 2018 and September 30, 2019 (index window) were identified in the Optum's CDM database and included for analysis if they met the 


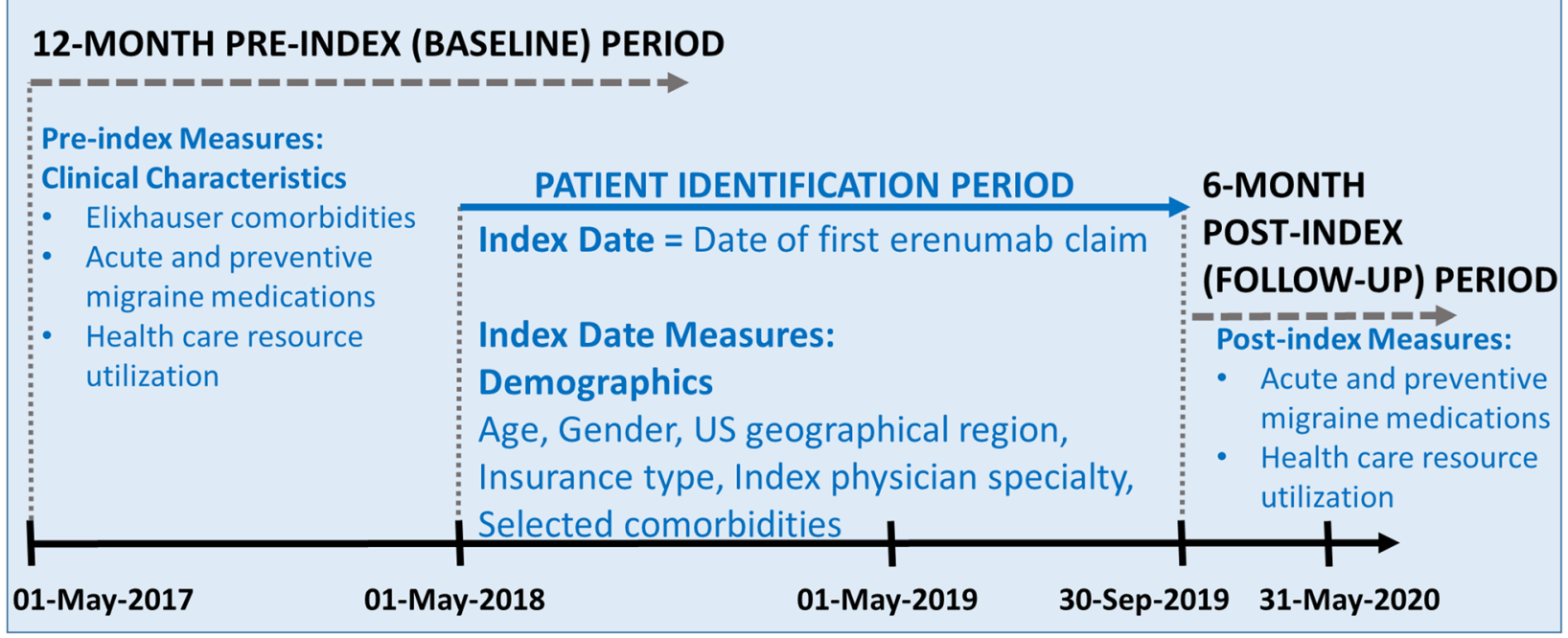

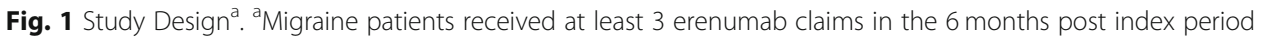

following study criteria: $\geq 1$ migraine diagnosis between May 1, 2017 and September 30, 2019; index claim (first erenumab claim served as the index date) dispensed from a pharmacy continuously submitting data to Optum's CDM during the 12 months prior to the index date and 6 months post-index period; and $\geq 3$ erenumab doses in the 6 months post-index period. Patients who received other non-erenumab anti-CGRP biologics during the 12-month pre-index or 6-month post-index period were excluded. A planned subgroup analysis further analyzed a cohort of patients receiving prior onabotA therapy during the 12-month pre-index period. The entire study period spanned from May 1, 2017 to March 30, 2020.

\section{Study measures \\ Patient characteristics}

Baseline demographics (age, age group, gender, geographic region, and insurance type) and erenumab prescriber specialty (neurologist/headache specialist, primary care provider $[\mathrm{PCP}]$, includes family practice and internal medicine], nurse practitioner [NP]/physician assistant $[\mathrm{PA}]$, psychiatrist/psychologist, other specialist, other HCP or unknown/missing) were measured on the index date. Baseline clinical features of 6 -month acute, 12-month preventive migraine medication use and comorbidities were measured prior to the index date. Selected comorbidities (such as, anxiety, cardiovascular disease, depression, insomnia, and constipation) were measured during the 12-month pre-index period (not including index date). The Elixhauser comorbidity score was assessed over the12month pre-index period [26].
Treatment patterns of acute and preventive therapies

The number and type of commonly prescribed acute medications (triptans, ergots, NSAIDs, opioids, and barbiturates) in the 6-month pre-index period, and preventive migraine prescription medications (onabotA, tricyclic antidepressants [TCAs], serotonin-norepinephrine reuptake inhibitors [SNRIs], selective serotonin reuptake inhibitors [SSRIs], beta-blockers, calcium-channel blockers, anticonvulsants, and angiotensin converting enzyme $[\mathrm{ACE}]$ inhibitors/angiotensin II receptor blockers [ARBs]) in the 12-month pre-index period, were assessed. As some of the acute and preventive medications are also approved for other conditions, a claim associated with a migraine diagnosis was required. The use of non-migraine specific acute medications (NSAIDs, opioids, and barbiturates) required a migraine diagnosis on, or within the 7 days prior to, the medication claim, and the use of non-migraine specific preventive medications required a migraine diagnosis on, or within 14 days prior to, the medication claim with at least 28 days of supply.

\section{Outcomes measures}

The impact of erenumab on acute medication usage during 6 months before and after erenumab treatment among patients with migraine was analyzed as follows: (1) the number of claims on acute medication; (2) proportion of patients with acute medication usage; and (3) the number of different types of acute medications used.

The impact of erenumab on HCRU during 6 months before and after erenumab treatment was measured as follows: (1) All-cause or migraine-specific emergency room (ER) visits or hospitalizations; (2) All-cause or migraine-specific office visits; (3) All-cause or migraine- 
specific neurologist or headache specialist visits; and (4) All-cause or migraine-specific other outpatient visits.

The impact of erenumab was also measured on a composite endpoint during 6 months before and after erenumab treatment of: (1) outpatient visit with a diagnosis of migraine and an associated acute medication claim; (2) hospital admission with a primary diagnosis for migraine; or (3) ER visit with a primary diagnosis for migraine. Any events that occurred $\leq 3$ days apart were counted only once.

A similar analysis was performed on the onabotA subgroup erenumab cohort.

\section{Statistical analyses}

All analyses were performed using $\mathrm{SAS}^{\oplus}$ studio 3.8 (Copyright $\odot$ 2018, SAS Institute Inc., Cary, NC, USA). Descriptive statistics were used to summarize patient characteristics. To compare 6-months before and after initiation of erenumab data, a negative binomial model with repeated measures was performed for count variables, such as the number of visits and claims, with rate ratios (RR) and 95\% confidence interval (CI) calculated; the McNemar test was performed for dichotomous variables; and a proportional odds model with repeated measurement was performed for ordinal variables to assess the odds of having a higher number of different types of acute medications. Means and standard deviations (SD) were reported for continuous measures, and frequencies and percentages were reported for categorical measures.

\section{Results}

\section{Patient population}

After applying inclusion and exclusion criteria, 3171 patients were identified as being eligible for inclusion in the overall study cohort (Fig. 2). Of these, 720 previous onabotA users were included in the subgroup analysis. Baseline characteristics of the overall and subgroup cohorts are presented in Table 1 . Patients in the overall cohort were majority female $(84.8 \%)$ with a mean $[S D]$ age

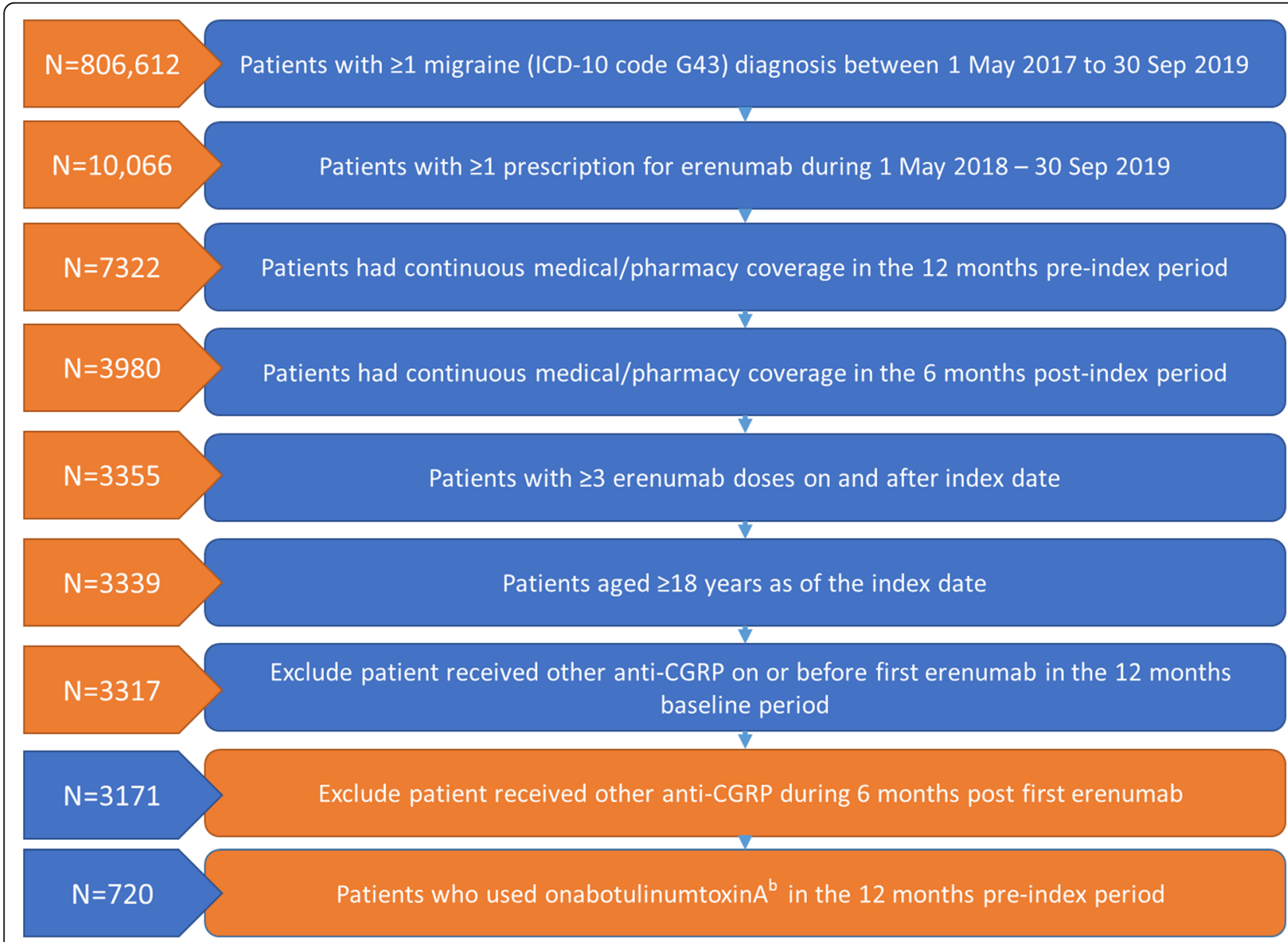

Fig. 2 Patient Identification Flowchart ${ }^{\mathrm{a}}$. Associated with a migraine diagnosis $\leq 14$ days post the first migraine diagnosis between 01-May-2018

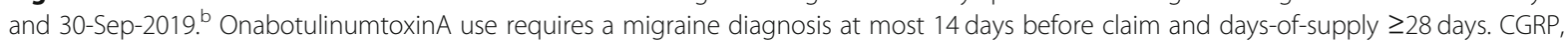
calcitonin gene-related peptide 
Table 1 Demographics/characteristics of the populations analyzed

\begin{tabular}{|c|c|c|}
\hline & $\begin{array}{l}\text { Erenumab } \\
\text { cohort } \\
(N=3171)\end{array}$ & $\begin{array}{l}\text { Onabot } A \\
\text { subgroup } \\
(N=720)\end{array}$ \\
\hline Age at index date, mean (SD) & $50.7(13.6)$ & $51.1(13.2)$ \\
\hline Female, n (\%) & $2689(84.8)$ & $628(87.2)$ \\
\hline CM in 12 month pre-index period, $\mathrm{n}(\%)$ & $1982(62.5)$ & $685(95.1)$ \\
\hline \multicolumn{3}{|l|}{ Index physician specialty, n (\%) } \\
\hline Neurologist/headache specialist & $2159(68.1)$ & $513(71.3)$ \\
\hline General practitioner & $439(13.8)$ & $78(10.8)$ \\
\hline Nurse/physician assistant & $293(9.2)$ & $68(9.4)$ \\
\hline Unknown/missing & $154(4.9)$ & $34(4.7)$ \\
\hline Other specialist & $59(1.9)$ & $11(1.5)$ \\
\hline Other HCP & $52(1.6)$ & $12(1.7)$ \\
\hline Psychiatrist/psychologist & $15(0.5)$ & $4(0.6)$ \\
\hline \multicolumn{3}{|l|}{ Region, n (\%) } \\
\hline South & $1536(48.4)$ & $301(41.8)$ \\
\hline West & $684(21.6)$ & $205(28.5)$ \\
\hline Midwest & $667(21.0)$ & $146(20.3)$ \\
\hline Northeast & $284(9.0)$ & $68(9.4)$ \\
\hline \multicolumn{3}{|l|}{ Insurance type, n (\%) } \\
\hline Point of service (POS) & $1569(49.5)$ & $359(49.9)$ \\
\hline Other & $741(23.4)$ & $179(24.9)$ \\
\hline Health maintenance organization (HMO) & $518(16.3)$ & $114(15.8)$ \\
\hline Exclusive provider organization (EPO) & $214(6.7)$ & $38(5.3)$ \\
\hline Preferred provider organization (PPO) & $129(4.1)$ & $30(4.2)$ \\
\hline \multicolumn{3}{|c|}{$\begin{array}{l}\text { Selected comorbidities in } 12 \text { month pre-index period (> 10\%), } \\
\text { n (\%) }\end{array}$} \\
\hline Anxiety & $1304(41.1)$ & $343(47.6)$ \\
\hline CV disease & $1298(40.9)$ & $304(42.2)$ \\
\hline Depression & $1295(40.8)$ & $337(46.8)$ \\
\hline Insomnia & $731(23.1)$ & $176(24.4)$ \\
\hline Obesity & $601(19.0)$ & $141(19.6)$ \\
\hline Fibromyalgia & $434(13.7)$ & $109(15.1)$ \\
\hline Constipation & $421(13.3)$ & $113(15.7)$ \\
\hline
\end{tabular}

$C M$ chronic migraine, $C V$ cardiovascular, $h c p$ health care practitioner, $n$ number, onabotA onabotulinumtoxinA, SD standard deviation, w/o without

of 50.7 [13.6] years and $62.5 \%$ had CM. Patients were weighted to the Southern (48.4\%) and West (21.6\%) regions of the US, and almost half (49.5\%) had point of service (POS) insurance. The prevalence of the selected comorbidities during the 12-month pre-index period were: anxiety (41.1\%), cardiovascular disease (40.9\%), depression (40.8\%), insomnia (23.1\%), and constipation (13.3\%). The mean Elixhauser comorbidity score in the 12 -month pre-index was 1.70 . The score is generated via the summation of points from each disease and the range of possible scores is from - 19 (lesser disease burden) to +89 (greater disease burden). Elixhauser comorbidities are shown in Supp Table 2.

Neurologists/headache specialists were the most common prescribers of erenumab, initiating $68.1 \%$ of the index prescriptions, followed by PCPs (13.8\%) and NPs/ PAs (9.2\%). Prior to initiating erenumab, $70.9 \%$ and $71.6 \%$ of patients were observed to have had an acute prescription medication for migraine in the 6-month pre-index period or preventive prescription medication in the 12-month pre-index period, respectively. The top four acute medication classes used were triptans (55.9\%), opioids (19.7\%), NSAIDs (7.4\%), and barbiturates (6.7\%) (Figs. 3 and 4). The top four preventive medication classes used were anticonvulsants (42.2\%), antidepressants (29.0\%), onabotA (22.7\%), and beta blockers (18.8\%) (Supp Table 3). Thirty-five percent of patients were prescribed one preventive migraine drug class, $23.7 \%$ were prescribed 2 drug classes, and $12.9 \%$ had 3 or more in the 12-months prior to initiating erenumab.

Similar trends were observed within the onabotA subgroup cohort. Patients were a similar age and gender, with $87.2 \%$ female and the mean [SD] age 51.1 [13.2] years (Table 1). However, the proportion with a $\mathrm{CM}$ without aura diagnosis was significantly higher in this subgroup (62.5\% in the overall population and $95.1 \%$ in the onabotA cohort). This is expected as onabotA is only approved for $\mathrm{CM}$ patients, and therefore, all of these onabotA patients should have had a CM diagnosis. Both groups had similar insurance type $(49.9 \%$ had POS insurance). The prevalence of selected comorbidities (anxiety, cardiovascular disease, and depression) during the 12 -month pre-index period was $47.6 \%, 42.2 \%$, and $46.8 \%$, respectively. Patients in this cohort experienced higher rates of anxiety $(41.1 \%$ vs $47.6 \%)$ and depression ( $40.8 \%$ vs $46.8 \%$ ) than in the overall cohort, potentially indicating more debilitating symptoms of attacks.

A slightly higher number of erenumab prescriptions were initiated by a neurologist/headache specialist in the onabotA vs overall cohorts, $(71.3 \%$ vs $68.1 \%$, respectively), and fewer PCPs initiated erenumab in the onabotA vs overall cohorts ( $10.8 \%$ vs $13.8 \%$, respectively). In $9.4 \%$ of cases, erenumab was initiated by NPs/PAs. All patients in this sub cohort (100\%) had pre-index use of preventive migraine medications, as they all received onabotA before initiating erenumab. The top four nononabotA preventive medication classes used were anticonvulsants (48.3\%), antidepressants (34.4\%), beta blockers (22.8\%), and calcium channel blockers (10.1\%). Twenty-eight percent of patients were prescribed one preventive migraine drug class, $35.4 \%$ were prescribed 2 drug classes, and $36.7 \%$ had 3 or more. Overall, $75.4 \%$ of patients used at least one acute medication during the 6month pre-index period. The top acute medications 


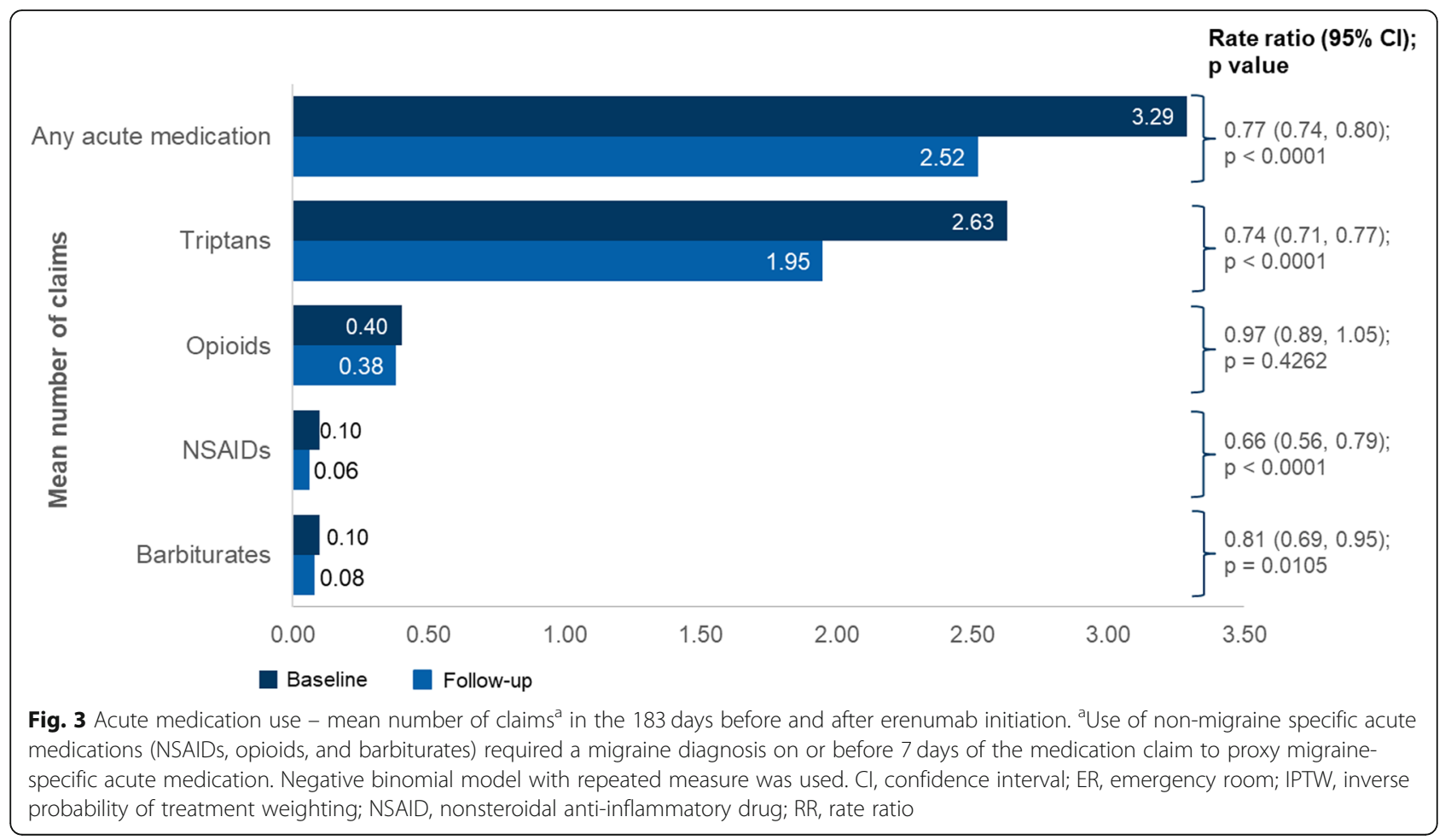

used were triptans (57.2\%), opioids (27.8\%), and NSAIDs (10.8\%) (Supp Fig. 1).

Patients in the onabotA subgroup were prescribed both acute and preventive medications more frequently than the overall population, and were prescribed a higher number of medication classes, indicating that this group experienced migraine episodes of greater severity and potentially greater migraine burden. It is worth noting that the US step edit requirements by payers for approval of erenumab and onabotA generally require




failure of two classes of preventive therapy and sometimes, inexplicably, a trial course of triptans. These requirements partially explain the more frequent acute and preventive category prescriptions, but the more frequent prescriptions still suggest greater disease severity and migraine burden or they would not be initiated for the patients.

\section{Acute medication usage and HCRU}

Comparing the 6 months pre-index period and the 6months post-initiation of erenumab, use of acute medication decreased significantly, with the mean number of claims [SD], declining from 3.29 [4.40] to 2.52 [3.78] (RR 0.77 [95\% CI: $0.74-0.80 ; p<0.0001]$ ), and the proportion of patients using acute medications reduced from $70.9 \%$ to $61.1 \%(p<0.0001)$ (Figs. 3 and 4$)$. Note the results for ergot use in the 6-month post-index period are not reported due to insufficient data. In addition, after receiving erenumab, patients had significantly lower odds of receiving one or more different types of acute medication vs baseline (OR 0.56; 95\% CI: 0.51-0.63; $p<0.0001$ when counting at the generic drug level and OR 0.57; 95\% CI: $0.51-0.64 ; p<0.0001$ when counting at the drug class level (Table 2)).

Similarly, 6 month HCRU decreased significantly, with the mean number of migraine-specific office visits [SD] decreasing from 2.56 [2.68] to 1.97 [2.24] (RR 0.77; 95\% CI: $0.74-0.80 ; P<0.0001)$, and the proportion of patients with migraine-specific office visits decreasing from $86.2 \%$ to $77.6 \%, P<0.0001$ (Fig. 5 and Supp Fig. 2). This significant reduction was similar for neurologist or headache specialist visits (RR 0.76, 95\% CI: $0.73-0.78 ; P<$ 0.0001 ) and other outpatient visits (RR 0.79, 95\% CI: $0.70-0.89 ; P<0.0001)$. A small insignificant reduction was also seen in ER/inpatient visits (RR 0.92, 95\% CI: $0.74-1.15 ; P=0.4657)$.
An exploratory analysis using the composite outcome (comprising [1] outpatient visit with a diagnosis of migraine and an associated acute medication claim, [2] hospital admission with a primary diagnosis for migraine, or [3] ER visit with a primary diagnosis for migraine), found a significant reduction in the mean [SD] number of events, decreasing from 1.03 [1.53] to 0.77 [1.48] (RR 0.75, 95\% CI: 0.71 to $0.79, P<0.0001$ ). Moreover, the proportion of patients with any of the three events also significantly decreased from $52.7 \%$ to $39.5 \%$, $P<0.0001$ (Fig. 6).

Analyses of the composite outcome for the onabotA subgroup reflected the results observed in the overall population. In this onabotA subgroup, following the initiation of erenumab, the use of acute medication decreased significantly at 6 months. The mean number of claims [SD] declined from 4.18 [5.57] to 3.31 [5.10] (RR 0.79; 95\% CI: $0.74-0.85 ; p<0.0001)$, and the proportion of patients using acute medications reduced from $75.4 \%$ to $66.5 \%(p<$ 0.0001) (Supp Fig. 1 and Supp Fig. 3). In addition, patients had significantly lower odds of receiving different types of acute medication vs baseline (OR 0.51; 95\% CI: 0.41-0.63; $p<0.0001)$ when counting in generic drug level and $\mathrm{OR}$ 0.56; 95\% CI: $0.46-0.70 ; p<0.0001$ when counting in drug class level (Supp Table 4)). Following initiation of erenumab, HCRU decreased significantly at 6 months. The mean number of migraine-specific office visits $[\mathrm{SD}]$ decreased from 3.99 [3.85] to 2.82 [2.90] (RR 0.70; 95\% CI: 0.66-0.75; $P<0.0001$ ), and the proportion of patients with migrainespecific office visits decreased from $88.1 \%$ to $82.2 \%$ ( $p<$ 0.0001) (Supp Fig. 4 and Supp Fig. 5). A significant reduction in the mean [SD] number of events was observed for the composite outcome from 1.57 [2.08] to 1.17 [2.04] (RR 0.74, 95\% CI: 0.68 to $0.82, P<0.0001)$. Moreover, the proportion of patients with any of the three events also decreased from $62.1 \%$ to $48.2 \%, P<0.0001$ (Supp Fig. 6).

Table 2 Number of acute medications by generic and drug class in the 183 days before and after index

\begin{tabular}{|c|c|c|c|c|c|c|}
\hline \multirow{2}{*}{$\begin{array}{l}\text { Erenumab cohort } \\
N=3171\end{array}$} & \multicolumn{2}{|l|}{ Baseline } & \multicolumn{2}{|c|}{ Follow-up } & \multirow[b]{2}{*}{$\mathrm{OR}^{\mathrm{a}}(95 \% \mathrm{Cl})$} & \multirow[b]{2}{*}{$P$ value } \\
\hline & Number & $\%$ & Number & $\%$ & & \\
\hline \multicolumn{7}{|c|}{ Number of generic drugs used } \\
\hline 0 & 872 & $27.5 \%$ & 1170 & $36.9 \%$ & $0.56(0.51-0.63)$ & $<0.0001$ \\
\hline 1 & 1333 & $42.0 \%$ & 1205 & $38.0 \%$ & & \\
\hline 2 & 610 & $19.2 \%$ & 514 & $16.2 \%$ & & \\
\hline $3+$ & 356 & $11.2 \%$ & 282 & $8.9 \%$ & & \\
\hline \multicolumn{7}{|c|}{ Number of drug classes used } \\
\hline 0 & 872 & $27.5 \%$ & 1170 & $36.9 \%$ & $0.57(0.51-0.64)$ & $<0.0001$ \\
\hline 1 & 1545 & $48.7 \%$ & 1387 & $43.7 \%$ & & \\
\hline 2 & 560 & $17.7 \%$ & 453 & $14.3 \%$ & & \\
\hline $3+$ & 194 & $6.1 \%$ & 161 & $5.1 \%$ & & \\
\hline
\end{tabular}

$O R$ odds ratio, $S D$ standard deviation

${ }^{\text {a }}$ roportional odds model was used 


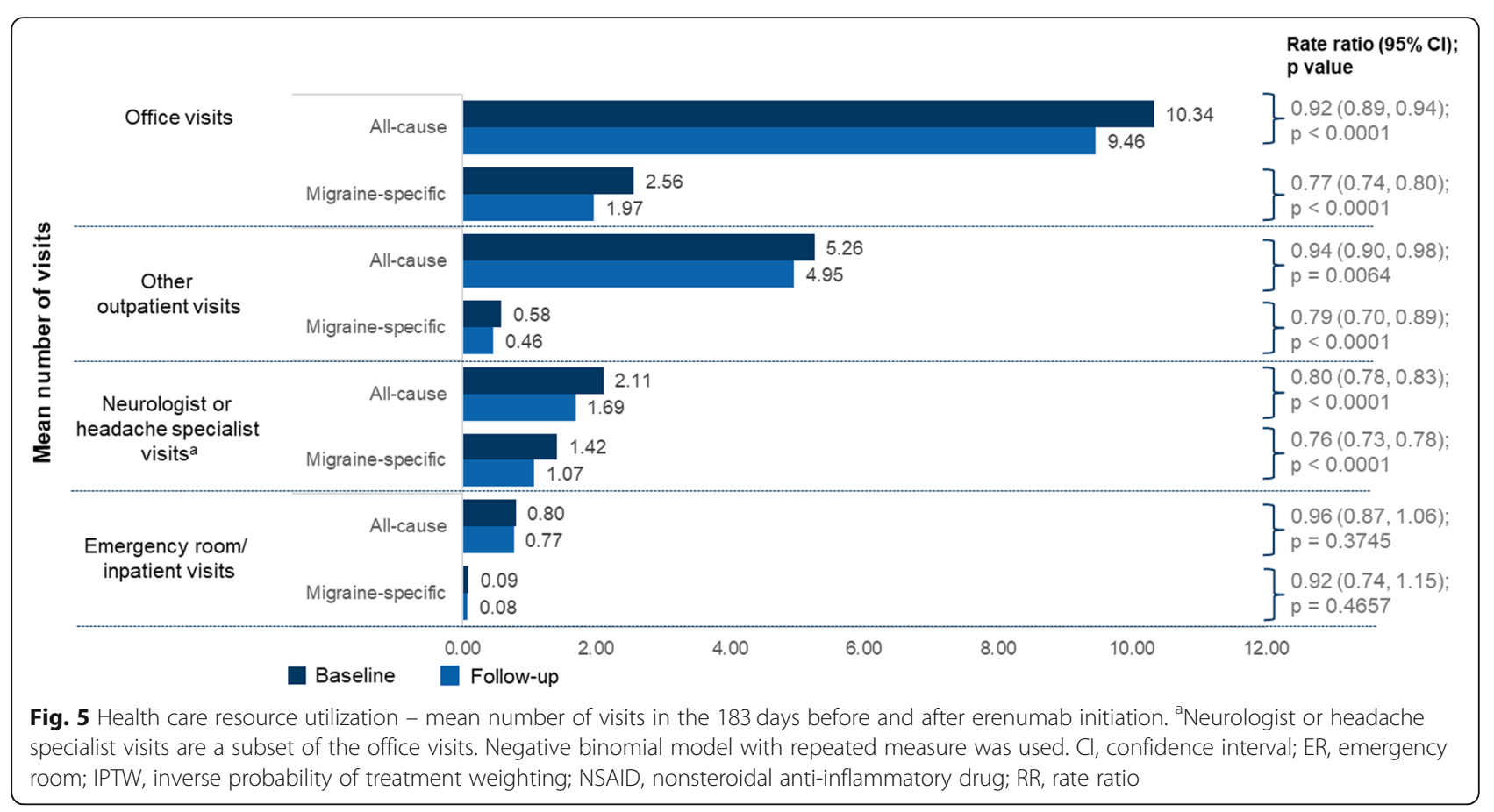

\section{Discussion}

We present a look at the real-world effectiveness of a first-in-class anti-CGRP agent (erenumab) approved for the prevention of migraine, on acute medication usage, HCRU, and a composite endpoint reflecting the overall burden of migraine. The population evaluated in these analyses represented patients initiating erenumab early in the post-approval period (with at least one erenumab prescription claim between May 1, 2018 and September $30,2019)$ identified from a large US database of administrative health claims for members of commercial and Medicare Advantage health plans. We assessed outcomes in an overall population comprising patients with at least three prescriptions for erenumab therapy. A separate cohort assessed the real-world effectiveness of erenumab in a subgroup of patients receiving prior onabotA therapy during 12-month pre-index period.

Migraine is a complex and long-term disabling neurological disease that is associated with recurrent and often debilitating headaches [27]. A single migraine attack typically disrupts the patient's life for $4-72 \mathrm{~h}[28,29]$. Migraines have an impact on patients' lives well beyond the pain they cause, and the burden of migraine is personal, economic, and societal [26]. Migraine treatment goals




are to relieve pain and restore function, reduce the frequency of migraine attacks, prevent transformation of EM to CM, expedite transformation from CM to EM and from acute medication overuse to non-overuse, and manage any existing comorbidities. Treatment decisions should be based on the frequency of migraines (EM or $\mathrm{CM}$ ), the level of impairment, previous treatment history, and patient preferences [30].

Acute therapies aim to provide a sustained pain-free response from the onset of an attack as quickly as possible (ideally within $2 \mathrm{~h}$ from onset), without recurrence, and with minimal adverse events [5, 31-35]. When acute treatments do not effectively control migraine symptoms, patients may escalate care with ER and/or specialist visits. In particular, evidence shows that HCRU and costs are mostly driven by outpatient visits (office and other outpatient visits) [3].

The use of migraine preventive treatments has been shown to reduce undesirable health outcomes and HCRU [36]. The role of preventive medications is to reduce frequency, severity, and duration of attacks, improve responsiveness to acute therapy, reduce migraine-related disability, and favorably impact the quality of life of migraine headaches [9-11]. Studies show that established migraine preventive options prior to 2018 were associated with high discontinuation rates due to tolerability issues and lack of efficacy [13-15]. In the US, a 2015 study reported that up to $83 \%$ of patients had discontinued the traditional preventive therapies within 12 months after initiation [11, 37-39]. A large proportion of patients prescribed preventive medications often have a history of prior medication failures, switching treatments, relying solely on acute medications, and overuse of acute medications. This can lead to increases in migraine frequency, transformation of EM to $\mathrm{CM}$, and occurrence of acute medication overuse headache $(\mathrm{MOH})$ [40, 41]. With effective preventive therapy, patients would not need to take as many acute medications, and the efficacy of acute medications would be improved; this would reduce the risk of acute medication tolerance/dependence, and $\mathrm{MOH}$ [42].

The results of this report suggested that over a period of 6 months, the initiation of erenumab significantly decreased the use of acute medication (RR 0.77; 95\% CI: $0.74-0.80 ; p<0.0001)$. Patients were less likely to require different classes of acute medications after being treated with erenumab (OR 0.57; 95\% CI: $0.51-0.64 ; p<0.0001)$. Similar outcomes were observed in the onabotA subgroup analysis (RR for preand post-index use of acute medication: 0.79 (95\% CI: $0.74-0.85 ; p<0.0001$, and OR 0.56 ; 95\% CI: $0.46-$ $0.70 ; p<0.0001$ when counting in different classes of acute medications).
Effective preventive therapy, therefore, has the potential to lessen the global economic burden of migraine by reducing outpatient visits and improving participation in everyday activities such as school and work, thereby reducing absenteeism and increasing productivity [43-45]. The economic burden of migraine, with health care and lost productivity costs associated with migraine, is estimated at $\$ 36$ billion annually in the US $[3,46]$. Given the widespread prevalence of migraine headache and the associated high rates of resource utilization, clinicians should make concerted efforts to reduce HCRU [4].

In this study, the initiation of erenumab significantly decreased HCRU of migraine-specific office visits (RR 0.77; 95\% CI: $0.74-0.80 ; P<0.0001)$ and all-cause office visits (RR 0.92; 95\% CI: $0.89-0.94 ; p<0.0001$ ). Similar outcomes were observed in the onabotA subgroup HCRU analysis (migraine-specific office visits: RR 0.70; 95\% CI: $0.66-0.75 ; p<0.0001$ and all-cause office visits: RR 0.89; 95\% CI: $0.85-0.93 ; p<0.0001)$. This reduction of at least $23 \%$ in HCRU is a very meaningful change, given the widespread prevalence of migraine and the associated high rates of resource utilization.

Erenumab significantly reduced the composite endpoint, which indicates an overall reduction in the burden of the disease in patients with migraine. The proportion of patients with any of the three events comprising the composite significantly decreased from $52.7 \%$ to $39.5 \%$, $P<0.0001$, and the mean [SD] number of events decreased from 1.03 [1.53] to 0.77 [1.48]. A composite endpoint such as the one reported in this study may potentially be used as a proxy to evaluate migraine attacks, although further research is needed.

\section{Limitations}

The use of claims data is subject to several limitations, and Optum's CDM is a US database. The results gained from claims analysis apply only to the insured population in the US, which may not be generalizable to the overall population, or to the international population. Claims data in the US are currently dependent on professional International Classification of Diseases (ICD) coding and not the International Classification of Headache Disorders, 3rd Edition (ICHD-3) and, therefore, some diagnoses may be missed, different professional types may have different coding patterns, and not all coding may be accurate. Further limitations of prescription claims data are that over-the-counter (OTC) exposure is missed, and a prescription does not always guarantee patient administration. Patients receiving erenumab from the free drug program are also not captured in the Optum's de-identified CDM database; thus, it is impossible to ascertain whether the first erenumab claim is truly indicative of the first time erenumab is used by a given patient. In these cases, the actual effectiveness 
might be larger than observed because baseline data may have been favorably affected by prior exposure to erenumab.

One further limitation is that this is a single arm study and it is difficult to account for regression to the mean.

In spite of these limitations, claims data are a valuable resource for exploratory analyses of a variety of health services research questions.

\section{Conclusions}

This research provides insight into real-world effectiveness of a first-in-class CGRP pathway-targeted mAb therapy for the prevention of migraine. Erenumab significantly reduces acute medication use on both number of claims and number of different classes, and HCRU in the real-world setting, hence significantly reducing the burden of the disease. A significant reduction of $25 \%$ on the composite endpoint of the outpatient visits with an acute medication claim and migraine-specific ER or inpatient visits shows the overall benefit of erenumab in the real-world. The personal, economic, and societal burden of migraine can be eased by improving acute care therapy and earlier treatment commencement of effective preventive therapy. A composite endpoint could be used as a proxy to evaluate migraine attacks, although further research is needed.

\section{Abbreviations}

ACE: Angiotensin converting enzyme; ARB: Angiotensin II receptor blockers; CDM: Clinformatics Data Mart; CGRP: Calcitonin gene-related peptide; Cl: Confidence interval; CM: Chronic migraine; EM: Episodic migraine; EPO: Exclusive provider organization; ER: Emergency room; GPP: Guidelines for Good Pharmacoepidemiology Practices; HCP: Health care professional; HCRU: Health care resource utilization; HIPPA: Health Insurance Portability and Accountability Act; HMO: Health maintenance organization; ICD: International Classification of Diseases; ICHD-3: International Classification of Head- 508 ache Disorders, 3rd Edition; ISPE: International Society for Pharmacoepidemiology; mAb: monoclonal antibody; MOH: Medication overuse headache; NSAID: Nonsteroidal anti-inflammatory drugs; NP: Nurse practitioner; onabotA: onabotulinumtoxinA; OR: Odds ratio; OTC: over-the-counter; PCP: Primary care providers; PA: Physician assistants; POS: Point of service; PPO: Preferred provider organization; RR: Rate ratio; SD: Standard deviation; SNRI: Serotonin-norepinephrine reuptake inhibitors; SSRI: Selective serotonin reuptake inhibitors; STROBE: Strengthening the Reporting of Observational Studies in Epidemiology; TCA: Tricyclic antidepressants; US: United States

\section{Supplementary Information}

The online version contains supplementary material available at https://doi. org/10.1186/s10194-021-01238-2.

Additional file 1: Supp Fig 1. Acute medication use - proportion of patients $^{a}$ in the 183 days before and after erenumab initiation. Supp Fig. 2. Health care resource utilization - proportion of patients in the 183 days before and after erenumab initiation. Supp Fig. 3. Acute medication use - mean number of claims ${ }^{\mathrm{a}}$ in the 183 days before and after erenumab initiation. Supp Fig. 4. Health care resource utilization mean number of visits in the 183 days before and after erenumab initiation. Supp Fig. 5. Health care resource utilization - proportion of patients in the 183 days before and after erenumab initiation. Supp Fig. 6. Composite endpoint $\mathrm{t}^{\mathrm{a}}$ in the 183 days before and after erenumab initiation. Supp Table 1. Diagnosis codes. Supp Table 2. Elixhauser Comorbidities $(\geq 5 \%)$. Supp Table 3. Baseline preventive drugs used in the 12 month pre-index period. Supp Table 4. Number of acute medications by generic and drug class in the 183 days before and after erenumab initiation.

\section{Acknowledgements}

Medical writing support was provided by Bronwyn Boyes and funded by Novartis.

\section{Authors' contributions}

SJT, JF, PV, AA, MF, MG contributed to study design, analysis of the data, writing the manuscript and the decision to publish the results. LZ AND YS conducted analysis, contributed to study design, analysis of the data, and writing the manuscript. All authors read and approved the final manuscript.

\section{Funding}

This study was supported by Novartis Pharma AG. Erenumab is co-developed by Amgen and Novartis.

\section{Availability of data and materials}

All data generated or analysed during this study are included in this published article [and its supplementary information files].

\section{Declarations}

\section{Ethics approval and consent to participate}

Not applicable. This study only used existing de-identified patient records and analyses of health care claims, data do not meet the definition of human subject research, so Institutional Review Board approval and patient informed consent were not required. No identifiable private information or protected health information was provided. This study was conducted in accordance with the Guidelines for Good Pharmacoepidemiology Practices (GPP) of the International Society for Pharmacoepidemiology (ISPE) 2016, the Strengthening the Reporting of Observational Studies in Epidemiology (STROBE) guidelines, and with the ethical principles laid down in the Declaration of Helsinki.

\section{Consent for publication}

Not applicable.

\section{Competing interests}

SJT reports grants for research (no personal compensation): Allergan, Amgen, ElectroCore, Eli Lilly, Lundbeck, Neurolief, Novartis, Satsuma, Zosano; Consultant and/or Advisory Boards (honoraria): Aeon, Align Strategies, Allergan/Abbvie, Alphasights, Amgen, Aperture Venture Partners, Aralez Pharmaceuticals Canada, Axsome Therapeutics, Becker Pharmaceutical Consulting, BioDelivery Sciences International, Biohaven, ClearView Healthcare Partners, CRG, CoolTech, Currax, Decision Resources, DeepBench, DRG, Eli Lilly, Equinox, ExpertConnect, GLG, Guidepoint Global, Healthcare Consultancy Group, Health Science Communications, HMP Communications, Impel, InteractiveForums, Krog and Partners, Lundbeck, M3 Global Research, Magellan Rx Management, Medicxi, Navigant Consulting, Neurolief, Nordic BioTech, Novartis, Pulmatrix, Reckner Healthcare, Relevale, SAI MedPartners, Satsuma, Slingshot Insights, Spherix Global Insights, Sudler and Hennessey, Synapse Medical Communications, System Analytic, Teva, Theranica, Thought Leader Select, Trinity Partners, XOC, Zosano; Salary: Dartmouth-Hitchcock Medical Center, American Headache Society, Thomas Jefferson University; CME honoraria: American Academy of Neurology, American Headache Society, Cleveland Clinic Foundation, Diamond Headache Clinic, Elsevier, Forefront Collaborative, Hamilton General Hospital, Ontario, Canada, Headache Cooperative of New England, Henry Ford Hospital, Detroit, Inova, Medical Learning Institute Peerview, Medical Education Speakers Network, Miller Medical Communications, North American Center for CME, Physicians' Education Resource, Rockpointe, ScientiaCME, WebMD/Medscape.

JF, PV, AA, MF, and MG are employees and shareholders of Novartis; LZ and YS were employed by KMK Consulting Inc., at the time of this study, which received funding from Novartis to conduct this study. 


\section{Author details}

${ }^{1}$ Geisel School of Medicine at Dartmouth, Hanover, NH, USA. ${ }^{2}$ Novartis Pharmaceuticals Corporation, East Hanover, NJ, USA. ${ }^{3}$ Novartis Pharma AG, CH-4002 Basel, Switzerland. ${ }^{4}$ KMK Consulting Inc., Morristown, NJ, USA.

\section{Received: 16 February 2021 Accepted: 1 April 2021}

\section{Published online: 19 April 2021}

\section{References}

1. GBD 2016 Disease and Injury Incidence and Prevalence Collaborators (2017) Global, regional, and national incidence, prevalence, and years lived with disability for 328 diseases and injuries for 195 countries, 1990-2016: a systematic analysis for the Global Burden of Disease Study 2016 [published correction appears in Lancet. 2017 Oct;390(10106):e38]. Lancet 390(10100): $1211-1259$

2. Headache Classification Committee of the International Headache Society (IHS) (2018) The International Classification of Headache Disorders, 3rd edition. Cephalalgia 38(1):1-211

3. Bonafede M, Sapra S, Shah N, Tepper S, Cappell K, Desai P (2018) Direct and indirect healthcare resource utilization and costs among migraine patients in the United States. Headache. 58(5):700-714. https://doi.org/10.1111/hea d. 13275

4. Silberstein SD (2015) Preventive Migraine Treatment. Continuum (Minneap Minn) 21(4 Headache):973-989

5. Tepper SJ, Diener HC, Ashina M, Brandes JL, Friedman DI, Reuter U, Cheng S, Nilsen J, Leonardi DK, Lenz RA, Mikol DD (2019) Erenumab in chronic migraine with medication overuse: subgroup analysis of a randomized trial. Neurology 92(20):e2309-e2320. https://doi.org/10.1212/WNL. 0000000000007497

6. American Headache Society. The American Headache Society Position Statement On Integrating New Migraine Treatments Into Clinical Practice. Headache. 2019;59(1):1-18. https://doi.org/10.1111/head.13456. Epub 2018 Dec 10. Erratum in: Headache. 2019:59(4):650-1. PMID: 30536394.

7. Konstantinos S, Vikelis M, Rapoport A (2020) Acute care treatment of migraine. J Neuroophthalmol 40(4):472-484. https://doi.org/10.1097/WNO. 0000000000001053

8. Reuter U (2018) A review of monoclonal antibody therapies and other preventative treatments in migraine. Headache. 58(Suppl 1):48-59. https://doi.org/10.1111/head.13302

9. Loder E, Burch R, Rizzoli P (2012) The 2012 AHS/AAN guidelines for prevention of episodic migraine: a summary and comparison with other recent clinical practice guidelines. Headache. 52(6):930-945. https://doi. org/10.1111/j.1526-4610.2012.02185.x

10. Hepp Z, Bloudek LM, Varon SF (2014) Systematic review of migraine prophylaxis adherence and persistence. J Manag Care Pharm 20(1):22-33. https://doi.org/10.18553/jmcp.2014.20.1.22

11. Woolley JM, Bonafede MM, Maiese BA, Lenz RA (2017) Migraine prophylaxis and acute treatment patterns among commercially insured patients in the United States. Headache. 57(9):1399-1408. https://doi.org/10.1111/head.13157

12. Blumenfeld AM, Bloudek LM, Becker WJ, Buse DC, Varon SF, Maglinte GA Wilcox TK, Kawata AK, Lipton RB (2013) Patterns of use and reasons for discontinuation of prophylactic medications for episodic migraine and chronic migraine: results from the second international burden of migraine study (IBMS-II). Headache. 53(4):644-655. https://doi.org/10.1111/head.12055

13. Ho TW, Edvinsson L, Goadsby PJ (2010) CGRP and its receptors provide new insights into migraine pathophysiology. Nat Rev Neurol 6(10):573-582. https://doi.org/10.1038/nrneurol.2010.127

14. Shi L, Lehto SG, Zhu DX, Sun H, Zhang J, Smith BP, Immke DC, Wild KD, Xu C (2016) Pharmacologic characterization of AMG 334, a potent and selective human monoclonal antibody against the calcitonin gene-related peptide receptor. J Pharmacol Exp Ther 356(1):223-231. https://doi.org/10.1124/ jpet.115.227793

15. Aimovig ${ }^{\circledR}$ (erenumab-aooe) [prescribing Information]. Amgen Inc., April 2020. Available at: https://www.pi.amgen.com/ /media/amgen/ repositorysites/pi-amgen-com/aimovig/aimovig_pi_hcp_english.ashx. Accessed 24 Aug 2020

16. Tepper $S$, Ashina M, Reuter $U$, Brandes $J$, Doležil $D$, Silberstein $S$, Winner $P$, Leonardi D, Mikol D, Lenz R (2017) Safety and efficacy of erenumab for preventive treatment of chronic migraine: a randomised, double-blind, placebo-controlled phase 2 trial. Lancet Neurol 16(6):425-434. https://doi. org/10.1016/S1474-4422(17)30083-2
17. Dodick DW, Ashina M, Brandes JL, Kudrow D, Lanteri-Minet M, Osipova V, Palmer K, Picard H, Mikol DD, Lenz RA (2018) ARISE: a phase 3 randomized trial of erenumab for episodic migraine. Cephalalgia. 38(6):1026-1037. https://doi.org/10.1177/0333102418759786

18. Reuter U, Goadsby PJ, Lanteri-Minet M, Wen S, Hours-Zesiger P, Ferrari MD, Klatt J (2018) Efficacy and tolerability of erenumab in patients with episodic migraine in whom two-to-four previous preventive treatments were unsuccessful: a randomised, double-blind, placebo-controlled, phase $3 \mathrm{~b}$ study. Lancet. 392(10161):2280-2287. https://doi.org/10.1016/S0140-6736(1 8) $32534-0$

19. Lipton RB, Tepper SJ, Reuter U, Silberstein S, Stewart WF, Nilsen J, Leonardi DK, Desai P, Cheng S, Mikol DD, Lenz R (2019) Erenumab in chronic migraine: patient-reported outcomes in a randomized double-blind study. Neurology. 92(19):e2250-e2260. https://doi.org/10.1212/WNL. 0000000000007452

20. Goadsby PJ, Reuter U, Hallström Y, Broessner G, Bonner JH, Zhang F, Wright IK, Chou DE, Klatt J, Picard H, Lenz RA, Mikol DD (2020) Oneyear sustained efficacy of erenumab in episodic migraine: results of the STRIVE study. Neurology. 95(5):e469-e479. https://doi.org/10.1212/WNL. 0000000000010019

21. Goadsby PJ, Reuter U, Hallström Y, Broessner G, Bonner JH, Zhang F, Sapra S, Picard H, Mikol DD, Lenz RA (2017) A controlled trial of Erenumab for episodic migraine. N Engl J Med 377(22):2123-2132. https://doi.org/10.1056/ NEJMoa1705848

22. Buse DC, Lipton RB, Hallström Y, Reuter U, Tepper SJ, Zhang F, Sapra S, Picard H, Mikol DD, Lenz RA (2018) Migraine-related disability, impact, and health-related quality of life among patients with episodic migraine receiving preventive treatment with erenumab. Cephalalgia. 38(10):16221631. https://doi.org/10.1177/0333102418789072

23. Talbot J, Stuckey R, Crawford L, Weatherby S, Mullin S (2021) Improvements in pain, medication use and quality of life in onabotulinumtoxinA-resistant chronic migraine patients following erenumab treatment - real world outcomes. Headache Pain 22(1):5. https://doi.org/10.1186/s10194-020-01214-2

24. Payne KA, Varon SF, Kawata AK, Yeomans K, Wilcox TK, Manack A, Buse DC, Lipton RB, Goadsby PJ, Blumenfeld AM (2011) The international burden of migraine study (IBMS): study design, methodology, and baseline cohort characteristics. Cephalalgia. 31(10):1116-1130. https://doi.org/10.1177/03331 02411410610

25. Martelletti P, Schwedt TJ, Lanteri-Minet M, Quintana R, Carboni V, Diener HC, Ruiz de la Torre E, Craven A, Rasmussen AV, Evans S, Laflamme AK, Fink R, Walsh D, Dumas P, Vo P (2018) My migraine voice survey: a global study of disease burden among individuals with migraine for whom preventive treatments have failed. J Headache Pain 19(1):115. https://doi.org/10.1186/s 0194-018-0946-Z

26. Austin SR, Wong YN, Uzzo RG, Beck JR, Egleston BL (2015) Why summary comorbidity measures such as the Charlson comorbidity index and Elixhauser score work. Med Care 53(9):e65-e72. https://doi.org/10.1097/MLR. Ob013e318297429c

27. Buse DC, Rupnow MF, Lipton RB (2009) Assessing and managing all aspects of migraine: migraine attacks, migraine-related functional impairment, common comorbidities, and quality of life. Mayo Clin Proc 84(5):422-435. https://doi.org/10.1016/S0025-6196(11)60561-2

28. Headache Classification Committee of the International Headache Society (IHS) (2013) The international classification of headache disorders, 3rd edition (beta version). Cephalalgia. 33(9):629-808. https://doi.org/10.1177/ 0333102413485658

29. Charles A (2013) The evolution of a migraine attack - a review of recent evidence. Headache. 53(2):413-419. https://doi.org/10.1111/head.12026

30. Lipton RB, Silberstein SD (2015) Episodic and chronic migraine headache: breaking down barriers to optimal treatment and prevention. Headache 55(Suppl 2):103-122. https://doi.org/10.1111/head.12505_2

31. Worthington I, Pringsheim T, Gawel MJ, Gladstone J, Cooper P, Dilli E, Aube M, Leroux E, Becker WJ, on behalf of the Canadian Headache Society Acute Migraine Treatment Guideline Development Group (2013) Canadian headache society guideline: acute drug therapy for migraine headache. Can J Neurol Sci 40(5 Suppl 3):S1-S3. https://doi.org/10.1017/S0317167100118943

32. World Health Organization (WHO) Atlas of headache disorders and resources in the world 2011: a collaborative project of World Health Organization and lifting the burden. 2011. Available from: http://www.who. int/mental_health/management/who_atlas_headache_disorders.pdf. Accessed 17 Nov 2020 
33. Freitag FG, Schloemer F (2014) Medical management of adult headache. Otolaryngol Clin N Am 47(2):221-237. https:/doi.org/10.1016/j.otc.2013.11.002

34. Weatherall MW (2015) The diagnosis and treatment of chronic migraine. Ther Adv Chronic Dis 6(3):115-123. https://doi.org/10.1177/204062231 5579627

35. Lanteri-Minet M (2014) Economic burden and costs of chronic migraine. Curr Pain Headache Rep 18(1):385. https://doi.org/10.1007/s11916-013-0385-0

36. Hepp Z, Dodick DW, Varon SF, Chia J, Matthew N, Gillard P, Hansen RN, Devine EB (2017) Persistence and switching patterns of oral migraine prophylactic medications among patients with chronic migraine: a retrospective claims analysis. Cephalalgia. 37(5):470-485. https://doi.org/1 $0.1177 / 0333102416678382$

37. Blumenfeld AM, Varon SF, Wilcox TK, Buse DC, Kawata AK, Manack A, Goadsby PJ, Lipton RB (2011) Disability, HRQoL and resource use among chronic and episodic migraineurs: results from the International Burden of Migraine Study (IBMS). Cephalalgia 31(3):301-315. https://doi.org/10.1177/ 0333102410381145

38. Hepp Z, Dodick DW, Varon SF, Gillard P, Hansen RN, Devine EB (2015) Adherence to oral migraine-preventive medications among patients with chronic migraine. Cephalalgia. 35(6):478-488. https://doi.org/10.1177/03331 02414547138

39. Berger A, Bloudek LM, Varon SF, Oster G (2012) Adherence with migraine prophylaxis in clinical practice. Pain Pract 12(7):541-549. https://doi.org/1 0.1111/j.1533-2500.2012.00530.x

40. Bigal ME, Lipton RB (2008) Excessive acute migraine medication use and migraine progression. Neurology. 71(22):1821-1828. https://doi.org/10.1212/ 01.wnl.0000335946.53860.1d

41. Yaldo AZ, Wertz DA, Rupnow MF, Quimbo RM (2008) Persistence with migraine prophylactic treatment and acute migraine medication utilization in the managed care setting. Clin Ther 30(12):2452-2460. https://doi.org/1 0.1016/j.clinthera.2008.12.010

42. Silberstein SD (2000) Practice parameter: evidence-based guidelines for migraine headache (an evidence-based review): report of the quality standards Subcommittee of the American Academy of neurology. Neurology. 55(6):754-762. https://doi.org/10.1212/WNL.55.6.754

43. D'Amico D, Solari A, Usai S, Santoro P, Bernardoni P, Frediani F, De Marco R, Massetto N (2006) Bussone G; Progetto Cefalee Lombardia group. Improvement in quality of life and activity limitations in migraine patients after prophylaxis. A prospective longitudinal multicentre study. Cephalalgia. 26(6):691-696. https://doi.org/10.1111/j.1468-2982.2005.01094.x

44. Bordini CA (2005) Mariano da Silva H, Garbelini RP, Teixeira SO, Speciali JG. Effect of preventive treatment on health-related quality of life in episodic migraine. J Headache Pain 6(5):387-391. https://doi.org/10.1007/s10194-0050233-7

45. Newman L, Huels J, Vo P, et al. Economic Burden Increased with Number of Treatment Failures in Migraine Patients - A Retrospective Claims Database Analysis in the United States. Presented at the American Academy of Neurology (AAN) 2020, Abstract S47.009

46. Marcus SC, Shewale AR, Silberstein SD, Lipton RB, Young WB, Viswanathan HN, Doshi JA (2020) Comparison of healthcare resource utilization and costs among patients with migraine with potentially adequate and insufficient triptan response. Cephalalgia. 40(7):639-649. https://doi.org/10.1177/03331 02420915167

\section{Publisher's Note}

Springer Nature remains neutral with regard to jurisdictional claims in published maps and institutional affiliations.

Ready to submit your research? Choose BMC and benefit from:
- fast, convenient online submission
- thorough peer review by experienced researchers in your field
- rapid publication on acceptance
- support for research data, including large and complex data types
- gold Open Access which fosters wider collaboration and increased citations
- maximum visibility for your research: over 100M website views per year
At BMC, research is always in progress.
Learn more biomedcentral.com/submissions

